\title{
Do you know this syndrome? Ichthyosis associated with neurological condition and alteration of hairs ${ }^{*}$
}

\author{
Luciana Baptista Pereira ${ }^{1}$ \\ Vanessa Barreto Rocha ${ }^{1}$
}

DOI: http:/ /dx.doi.org/10.1590/abd1806-4841.20187727

\section{CASE REPORT}

We present a three-year-old male patient, with dry skin since birth and onset of scaling at 4 months of life. The patient had hypoplastic, low implanted nipples, hypogonadism, microcephaly, frontal bossing, prominent ears, anteverted nares, receding chin, dental enamel changes, joint contractures and umbilical hernia (Figure 1).

On dermatological examination, there was an ichthyosiform peeling of the skin all over the body, photosensitivity, coarse, thick and short scalp hair, darker, short and coarse eyebrow hair, nail clubbing and thinning, and reduced subcutaneous fatty tissue (Figures 1 and 2). He also presented with recurrent eczematous lesions, mainly on the folds.

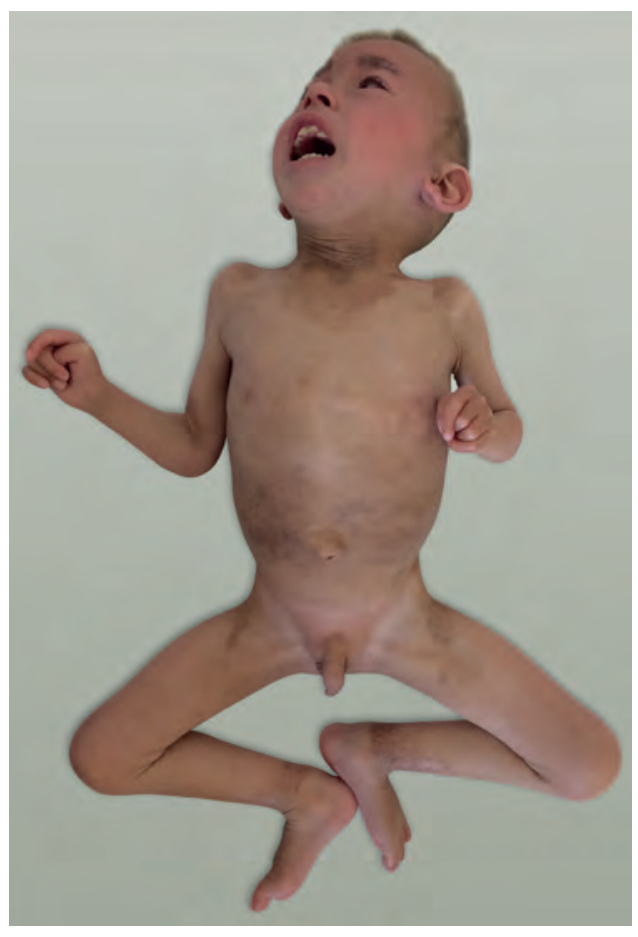

Figure 1: Ichthyosiform peeling, hypoplastic and low implanted nipples, umbilical hernia, joint contractures and reduction of the subcutaneous tissue

\author{
Neusa Yuriko Sakai Valente ${ }^{2}$
}

He progressed with short stature and marked delay in the neurologic and psychomotor development, spasticity, paraplegia, ophthalmologic disturbances (esotropia), episodes of bronchospasm and intestinal constipation.

There was parente consanguinity (second degree cousins) and no family history of similar cases.

Radiograph showed microcrania and decreased bone density. Brain computed tomography revealed brain of reduced size and periventricular leukomalacia. Echocardiogram showed no abnormalities.

Hair microscopy showed structural changes of the shaft, such as trichorrhexis nodosa, trichoschisis and pili torti (Figure 3). Polarized light examination revealed dark bands alternating with light bands in a "tiger tail" pattern (Figure 4).

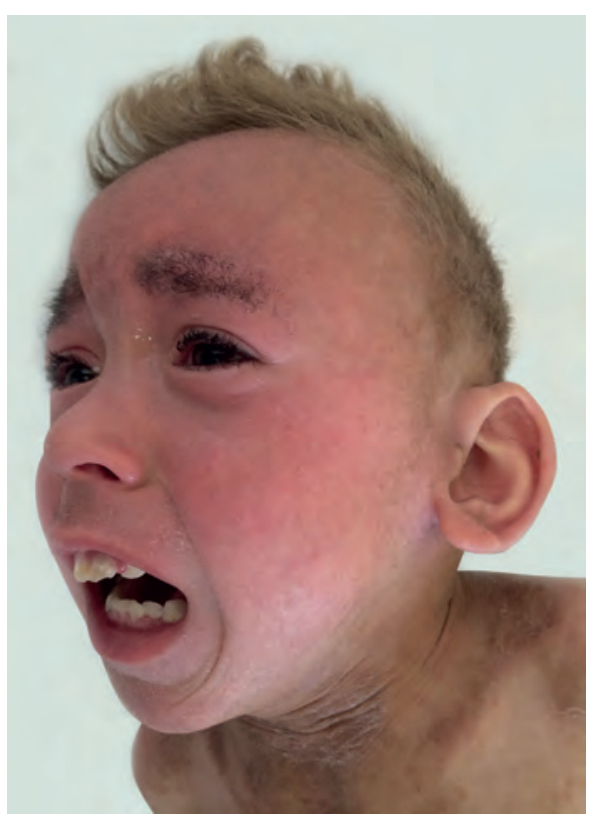

FigURe 2:

Dry and coarse hair. Eyebrow hair and eyelashes are darker, thick and coarse. And, microcephalus, frontal bossing, low implantation of the ears, short and illdemarcated nasal philtrum, small chin, dental enamel changes

Received on 08.10.2017.

Approved by the Advisory Board and accepted for publication on 02.11.2017.

Study performed at the Department of Dermatology, Hospital das Clínicas da Universidade Federal de Minas Gerais (HC-UFMG) - Belo Horizonte (MG), Brazil. Financial support: None.

Conflict of interest: None.

1 Department of Dermatology, Hospital das Clínicas da Faculdade de Medicina da Universidade Federal de Minas Gerais (UFMG) - Belo Horizonte (MG), Brazil. Department of Dermatology, Hospital das Clínicas da Faculdade de Medicina da Universidade de São Paulo (HC-FMUSP) - São Paulo (SP), Brazil. 


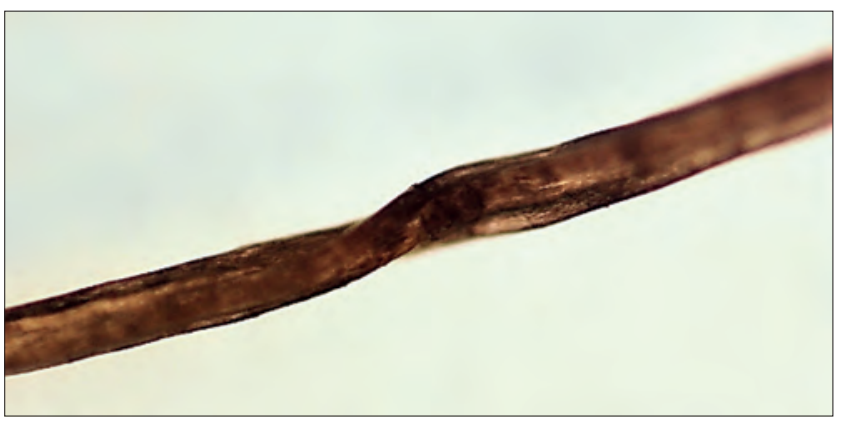

FigURE 3: Hair microscopy showing dark and light bands, pili torti

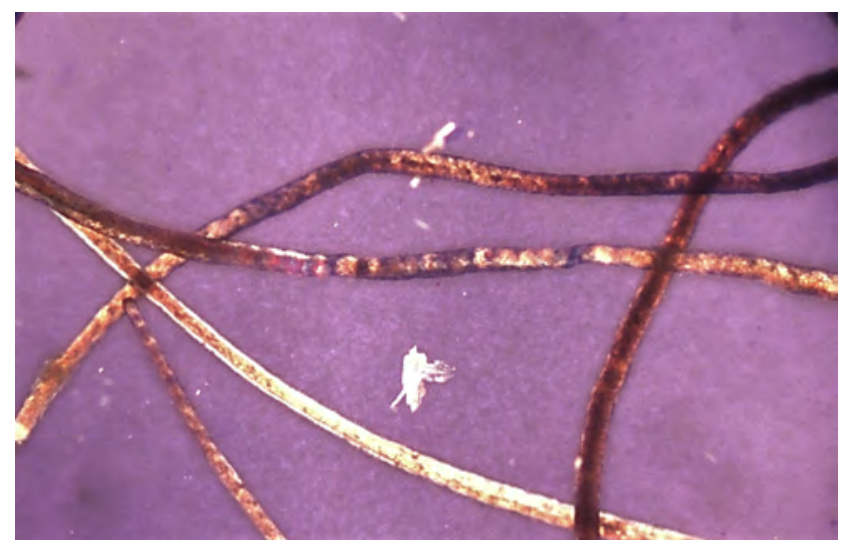

FIGURE 4: Hair microscopy under polarized light showing alternating light and dark bands, typical of the "tiger tail" pattern

\section{DISCUSSION}

Trichothiodystrophy is a term originated from the Greek (tricho, hair; thio, sulfur; dys, lack; trophe, trophic) that was introduced by Price et al. (1980) to describe a group of genetic disorders characterized by the presence of brittle, coarse hair due to sulfur deficiency and other neuroectodermal abnormalities, such as mental and growth retardation, susceptibility to infections, ichthyosis, nail changes, decreased fertility and premature aging. ${ }^{1-3}$

It is a heterogeneous group of diseases that currently comprise six groups, three of which are associated to photosensitivity. ${ }^{1,2,4}$ In most cases, the inheritance is autosomal recessive, but there are cases where it is autosomal dominant or X-linked dominat. ${ }^{1}$ In the cases with photosensitivity, there are mutations in the genes of the NER (nucleotide excision repair) pathway, and most of them are mutations in the xeroderma pigmentosum $\mathrm{D}$ gene, also known as ERCC2 gene, a subunit of the DNA repair/transcription factor. ${ }^{1,4-6}$ Contrary to other syndromes with photosensitivity, these defects do not result in an increased cancer incidence. ${ }^{4}$

Disease expressivity is largely variable, with a large severity spectrum. ${ }^{1,2}$ It mainly affects neuroectodermal tissues. Many cutaneous manifestations are described: ichthyosis, photosensitivity, ecze- ma, freckles, dystrophic oy hypoplastic nails. Facial dysmorphisms such as large ears, micrognathia, bird face, epicanthal folds, frontal bossing, hypotelorism or hypertelorism and ogival palate are seen. Neurologic disturbances are common: growth and development retardation, motor or intellectual difficulties, microcephaly, ataxia, neurosensory deafness, spasticity, paresis or paralysis, dysarthria, among others. Demyelination, atrophy cortical and/ or cerebellar atrophy, dilated ventricles and calcifications can be seen on imaging studies. Cataracts, nystagmus, strabismus, photophobia, ectropion are among the ocular manifestations. Skeletal abnormalities, such as osteosclerosis, osteopenia, kyphosis, joint contractures and teeth abnormalities with enamel hypoplasia and increased number of caries are described. Cardiac and hematologic abnormalities, hypogonadism and recurrent infections can also occur. ${ }^{5-9}$

Hairs are short, brittle and coarse. Under polarized light, the "tiger tail" pattern can be seen (alternating dark and light bands), ${ }^{5,8}$ It is possible to measure sulfur or amino acid levels, where mainly low levels of cysteine can be detected. ${ }^{8}$ 
Abstract: Trichothiodystrophy refers to a heterogeneous group of rare genetic diseases that affects neuroectodermal-derived tissues with multisystem involvement. The hallmark of these syndromes is the deficiency of sulfur in hair matrix proteins, leading to short and brittle hair. Few cases of this rare disorder have been published. The authors report a case of trichothiodystrophy in a male infant with ichthyosis, photosensitivity, spastic paraparesis, short stature, and neurologic and psychomotor retardation. Diagnosis was based on clinical and microscopic features of hair samples.

Keywords: Genetics; Ichthyosis; Trichothiodystrophy Syndromes

\section{REFERENCES}

1. Omin.org [Internet]. Trichothiodystrophy 1, photosensitive; TTD1. OMIM (Online Mendelian Inheritance in Man). Johns Hopkins University; Inc.;1966-2017 [updated 2016 0ct 26; cited 2017 0ct 10]. Available from: http://www.ncbi.nlm.nih.gov/.

2. Omin.org [Internet]. Trichothiodystrophy 3, photosensitive; TTD3. OMIM (Online Mendelian Inheritance in Man). Johns Hopkins University; Inc.;1966-2017 [updated 2016 0ct 25; cited 2017 0ct 10]. Available from: http://www.ncbi.nlm.nih.gov/.

3. Stefanini M, Botta E, Lanzafame M, Orioli D. Trichothiodystrophy: from basic mechanisms to clinical implications. DNA Repair (Amst). 2010;9:2-10.

4. Yew YW, Giordano CN, Spivak G, Lim HW. Understanding photodermatoses associated with defective DNA repair: Photosensitive syndromes without associated cancer predisposition. J Am Acad Dermatol. 2016;75:873-882.

5. Farmaki E, Nedelkopoulou N, Delli F, Sarafidis K, Zafeiriou DI. Brittle Hair, Photosensitivity, Brain Hypomyelination and Immunodeficiency: clues to trichothiodystrophy. Indian J Pediatr. 2017;84:89-90.
6. Brauns B, Schubert S, Lehmann J, Laspe P, Körner A, Brockmann K, et al. Photosensitive form of trichothiodystrophy associated with a novel mutation in the XPD gene. Photodermatol Photoimmunol Photomed. 2016;32:110-2.

7. Faghri S, Tamura D, Kraemer KH, Digiovanna JJ. Trichothiodystrophy: a systematic review of 112 published cases characterises a wide spectrum of clinical manifestations. J Med Genet. 2008;45:609-21.

8. Jiménez-Puya R, Moreno-Giménez JC, Camacho-Martínez F, Ferrando-Barbera J, Grimalt R. Trichothiodystrophy: PIBIDS syndrome. Actas Dermosifiliogr. 2007;98:183-7.

9. Itin PH, Sarasin A, Pittelkow MR. Trichothiodystrophy: update on the sulfurdeficient brittle hair syndromes. J Am Acad Dermatol. 2001;44:891-920.

How to cite this article: Pereira LB, Valente NYS, Rocha VB. Do you know this syndrome? Ichthyosis associated with neurological condition and alteration of hairs. An Bras Dermatol. 2018;93(1):135-7. 